\title{
Peer Review - Legal and Ethical Issues Faced by Medical Staff: The Mandate for Physician Leadership
}

\author{
Zachary R. Paterick ${ }^{1}$, Timothy E. Paterick ${ }^{*}$ \\ ${ }^{1}$ Law School, University of Michigan, Ann Arbor, Michigan, USA \\ ${ }^{2}$ Aurora BayCare Medical Center, Green Bay, Wisconsin, USA
}

*Corresponding Author: Timothy E. Paterick, MD, JD, MBA, Bay-Care Clinic, Green Bay, Wisconsin, USA.

Tel: +1-9044764233, Email: tpaterick@gmail.com

Received March 15, 2019; Accepted August 11, 2019; Online Published August 26, 2019

\begin{abstract}
Physicians working in hospitals face challenges when it comes to understanding and meeting the medical, legal, and ethical subjects outlined in the hospital bylaws. Hospital staff physicians and the hospital administration both aspire for high quality medical care and the assurance of patient safety. Unfortunately, when quality concerns surface, there can be reasonable differences of opinion as to whether a physician's practice pattern met the accepted threshold of the standard of care. Such differences of opinion can lead to conflict that fuels a physician review. One complication for physicians is that many of the issues that surface at peer reviews are veiled in legal concepts and underpinnings for which physicians lack education, training, and familiarity. It would be prudent for all physicians working in hospitals to become familiar with the hospital bylaws and regulations. Physicians must take a leadership role in assuring fair and equitable peer review.

Keywords: Peer Review, Quality Assurance, Patient Safety, Ethics
\end{abstract}

\section{Introduction}

Physicians are thrust into the world of peer review without the education and training in the legal and ethical principles that are inherent to a fair and trusted peer review process. Physicians must comprehend that the purpose of peer review is to "evaluate professionally a colleague's work." In medicine, peer review is defined as "the objective evaluation of the quality of a physician's performance by colleagues."2 An honest and fair peer review process is the staple of an excellent medical staff.

During a peer review, the reviewing physicians must pursue all the relevant facts and determine their veracity. Typical allegations against physicians are practice patterns that do not meet the standard of care or behavioral patterns that do not meet the accepted behavioral standards of the hospital. Medical staff members reviewing a colleague must proceed in a fair and honest manner. A fair and equitable peer review process is essential for a hospital that wants high quality medical care and a safeguard for patient safety.

Organized medicine employs the peer review process as a methodology to gauge professional activities and conduct. Physicians have an ethical and moral responsibility to each other and to patients to assure all hospital practice patterns meet the standard of care. The peer review committee must allow physicians the right to exercise freedom in their medical judgment but ensure that the medical judgment is accepted and consistent with the national standards of care.

Disciplinary hearings where a physician's reputation, professional status, or livelihood is at risk must be objective and fair. To be objective and fair, the hearings must include the following:

- A list of alleged wrongdoings;

- Adequate notice of the right to a hearing;

- The right to defend one's actions;

- Reviewing physicians that have a similar scope of practice as the physician under review.

All reviewing physicians must disclose any conflicts of interest and recuse themselves when conflicted for any reason. The hospital bylaws and administration must ensure safeguards that guarantee all physicians due process when enduring a peer review.

\section{Why Physicians Need to Develop a Deep Understanding of the Peer Review Process}

The importance of a fair and equitable peer review process is never so self-evident until a physician is the subject of one. The birth of peer review conceptually started with Ernest Amory Codman. He was an extraordinary surgeon at Massachusetts General Hospital who was ahead of his time. His true passion was the science of quality improvement. Codman was a surgeon who believed that

Copyright (C) 2019 The Author(s). This is an open-access article distributed under the terms of the Creative Commons Attribution License (http:// creativecommons.org/licenses/by/4.0), which permits unrestricted use, distribution, and reproduction in any medium, provided the original work is properly cited. 
by prospectively tracking outcomes, we could learn from patient results and advance the field of medicine. He helped develop the concepts integral to present-day morbidity and mortality conferences and started the first national registry in American healthcare. ${ }^{3}$

Given the challenges of medicine today with ever increasing rates of errors and wide variability in quality, ${ }^{4}$ many physicians are requesting that Codman's basic tenants be revisited and applied. Codman described patient tracking in a publicly circulated pamphlet in 1914: "Every hospital should monitor every patient it treats long enough to determine whether the treatment has been successful, and then inquire 'if not, why not' with a review to identify root causes of failure with a view to preventing similar failures in the future." ${ }^{5}$

The approach to peer review today had its seeds germinate in the early 1990s when the American College of Surgeons implemented peer review to define the standard of care requirements to be met by medical staff physicians. ${ }^{6}$ The peer review process today includes a peer review committee composed of staff physicians who report to a board of directors. The crucial decision-making authority is the board of directors after an examination of the peer review committee's judgment regarding the charged allegations. ${ }^{7}$ As envisioned by Dr. Codman, this peer review process is required by JCAHO for hospital accreditation. ${ }^{8}$

\section{What Prompts a Peer Review?}

Peer reviews may be instigated in US hospitals for several reasons. It is expected that hospitals will initiate a peer review of physicians requesting hospital privileges to determine whether the physicians have the necessary education and training to perform the requested privileges. A second basis for peer review is the allegation that a physician is practicing below the standard of care. A third reason is that a physician is acting outside the boundaries of normally accepted hospital behavior. A fourth reason for a peer review is the random selection of cases to improve the overall quality of patient care. Lastly, a peer review may be prompted by adverse outcomes to determine the root causes of errors and develop processes to prevent future adverse events. ${ }^{7}$ Across the United States, the lack of a standardized peer review process has allowed varying decisions for similar alleged wrongdoings. This lack of standardization is a major issue that must be confronted by physician leaders.

\section{The Significance of the Patrick Case for Peer Review}

The personification of a fraudulent peer review is seen in the case of Dr. Timothy Patrick. Dr. Patrick, a vascular surgeon, sued Columbia Memorial Hospital (CMH) after he was subjected to a deceitful peer review for economic reasons. ${ }^{9}$ Patrick had joined a group practice in Astoria, Oregon. After several years with the group, he elected to decline partnership and pursue his own practice in the same geographic region. His previous colleagues reported
Patrick to the hospital executive committee at $\mathrm{CMH}$ for a peer review, asserting "irresponsible behavior" in his medical care of patients. The peer review committee was chaired by a member of the group Patrick left to pursue his own practice. An investigation of the alleged "irresponsible behavior" took place, and the committee voted to terminate Patrick's hospital privileges. ${ }^{9}$

A federal antitrust lawsuit was filed by Patrick against the Astoria clinic physicians claiming the defendants partook in a bad faith peer review to quash competition..$^{10}$ The United States Supreme Court ruled in favor of Patrick. ${ }^{10}$ This ruling by the highest court in the land had an unnerving affect upon physicians' willingness to participate in peer reviews. Physicians perceived themselves at a magnified legal risk if they participated in a review that ultimately was determined to be a sham. This fear emanated from the Supreme Court decision awarding Patrick a \$2.2 million verdict.

The Patrick decision had a huge negative impact on the necessary and important peer review process. The response to this physician reticence was congressional action introducing the Health Care Quality Improvement Act (HCQIA). This act resulted in physician immunity when participating in peer reviews, subject to several factors:

- that the purported allegations brought to the peer review committee were a furtherance of quality of care issues;

- that there would be a due diligence approach to fact finding;

- $\quad$ and that there would be adequate notice and a fair hearing procedure offered to the physician under review.

The introduction of HCQIA transformed the law granting peer review committees and hospitals limited immunity to almost unqualified immunity. ${ }^{11}$ This transformative congressional ruling created a situation of grave trepidation for physicians working in a setting of intense marketplace competition, where attempts are made by hospitals to stifle competition in order to control the marketplace. Today, sham reviews still occur, and the courts are often considered kangaroo courts when considering interference of competition issues. ${ }^{12}$ Courts often view hospitals as virtuous entities that are solely interested in quality medical care and patient safety, and they assume that the hospital administration wants to uncover and address all medical errors and safety issues that occur in the hospital so they could be prevented in the future. This suggests a "blind justice," called the "rule of non-review." This acknowledges the "business judgment rule," implying that the governing board of a private entity, like a hospital, has the right to determine and direct its own internal business and medical affairs. ${ }^{13}$ Ernest Codman must be rolling over in his grave! This type of public policy mandates that physician leaders engage in the peer review process to ensure that peer review is honest, fair, and equitable. 


\section{The Essence of Peer Review}

Physicians in the United States accept peer review, but there is some distrust because of a lack of understanding of the legal underpinnings of the peer review process. Health insurance companies have made a huge impact on the peer review process. They are now mandating evidence of quality peer review activity among the doctors in an institution prior to entering into an arrangement with the group of doctors or with the hospital.

The mission statement of the hospital often asserts that the institution aspires to a unified goal of transparency and partnership between the medical staff and the hospital administration to ensure equitable treatment of all disputes arising between a physician and the medical staff. Unfortunately, there are situations where the physician brought into the process and the medical staff has differing opinions about the alleged practice pattern and whether it meets the accepted standard of care. The complexity for physicians is that many issues of a peer review are veiled in legal concepts, in which physicians lack education, training, and familiarity.

The peer review process presents a varied range of issues that warrants legal knowledge and insights. It is imperative to have legal counsel when developing the foundation of the peer review process to assure that ethical, legal, and accreditation principles are developed. Physician leadership must play a critical role in meeting this goal, so that physicians are assured of equity and fairness. This approach is epitomized in an Arkansas statute ${ }^{14}$ that provides that medical staff can, as a matter of law, "engage independent legal counsel to review a professional review action before a final recommendation is made or final action taken." 15 This is particularly important for physicians who are not hospital employees and may represent competition to the employed hospital physicians. All physicians deserve a fair and equitable hearing process and must have the ability to appeal any decisions that impact reputation, professional status, or livelihood.

\section{Hearings and Appeals}

The peer review process quickly identifies the polarity between the physician subject to peer review and the investigative group of physicians. A hearing officer is appointed to preside over the process and offer advice to the hearing committee. The peer review committee's decision can be appealed to the hospital board of directors, which either makes the final decision or makes a recommendation to the peer review committee for the final decision.

It is problematic that hospital attorneys often represent the peer review committee and offer advice. The physician facing allegations may request that the peer review body use counsel not employed by the hospital or from a firm utilized by the hospital. This was highlighted in Yaqub vs. Salinas Memorial Healthcare System, ${ }^{15}$ in which the court warned that it would strain the due process clause to allow the hospital attorney, who took an active role in assisting the medical executive committee to bring charges against the appellant, to serve as an advisor to the board in the hearing. This type of judicial commentary is advocating for a true due process under the law, and it is crucial for physician leaders to understand this ruling.

\section{Credentialing and Privileging}

Credentialing and privileging are fundamental duties of a medical staff peer review and are essential to building a trustworthy and competent medical staff. The process can result in differences of opinion as to what privileges will be granted and whether a physician has the credentials to be on the medical staff. Today it is common practice for hospitals to recruit physicians as employees, which can lead to conflict between private practice physicians and employed physicians resulting in "tribalism" between employed and non-employed hospital staff members and potentially leading to prejudiced evaluations in credentialing and privileges. In jurisdictions recognizing negligent credentialing as a cause of action, ${ }^{16}$ the hospital's interest in defending itself against these claims may conflict with the medical staff's interest in protecting the confidentiality of the peer review process.

\section{Medical Staff Bylaws}

Generally the recognized "majority view" is that medical staff bylaws are interpreted as a contract between the hospital and the medical staff. ${ }^{17}$ Even in those jurisdictions where the bylaws are not contractual in nature, differences in opinion between hospital and staff may lead to the need for a process allowing full hearings overseen by impartial judges. Thus, the hospital bylaws must allow active medical staff members to vote on their ability to participate in the elaboration of the rules and regulations impacting physicians, which only the hospital executive committee can act upon. Thus, it is incumbent upon the medical staff to hire independent counsel to review medical staff bylaws to ensure that they contain provisions that allow due process and equitable treatment of all staff members and to attain physician membership on the executive committee.

\section{Standardization of Peer Review}

The need for standardization of the peer review process is epitomized in the Patrick case, where a sham review required Dr. Patrick to go to the Supreme Court for fairness and equity. Additionally, studies beyond the case example of Patrick have demonstrated that peer reviews are often unreliable measures of quality and have not served the envisioned function of quality improvement. Regulation of peer reviews should result in a two-fold effect: improvement in quality and decreased abuse of the process through sham reviews. ${ }^{18}$ National standardization efforts for peer reviews remain challenging, as the process is costly, time intensive, and requires extensive resources. Several models at diverse US hospitals have shown that standardization and structuring of the review process can improve medical care. ${ }^{19}$ Another approach is to develop additional protection of the peer review process involving 
external review to verify that the actions taken are in agreement with JACHO and HCQIA requirements.

\section{Conclusion}

Peer review, hearing and appeals procedures, credentialing and privileging, and medical staff bylaws are all critical to the fair and equitable treatment of physicians participating on medical staffs. Given the present healthcare landscape, it is imperative that all physicians take the time to understand the peer review process and to become knowledgeable in legal concepts that are imbedded in the interchange between the medical staff and the governance of the hospital board. It is prudent to have legal counsel review the contractual relationship between the medical staff and the hospital executive committee. A fair and honest peer review process is in the best interest of all participants on the medical staff and of the patients. It is imperative that physician leaders understand the history of sham reviews as highlighted in the Patrick case. Physician leaders must assure all physicians on hospital staffs receive fair and equitable treatment when issues are presented to a peer review committee.

The intense competition for patients in the medical marketplace and the highly politicized US healthcare system have been of concern to physicians seeking a fair and equitable peer review process. The immunity granted to peer review committees through the HCQIA has the potential to have a devastating effect on a physician's professional status or livelihood. Considering congressional and judicial tolerance of this quandary, substantial and meaningful physician leadership is necessary to remedy the potential deficiencies of the present-day peer review process. Furthermore, further research is needed to study the peer review process and its outcomes to determine if peer review reforms have altered the prevalence of sham reviews, improved the quality of care, and ensured patient safety.

\section{Authors' Contributions}

Both authors contributed equally to this study.

\section{Conflict of Interest Disclosures}

The authors declare that they have no conflicts of interest.

\section{References}

1. Vyas D, Hozain AE. Clinical peer review in the United States: history, legal development and subsequent abuse. World J Gastroenterol. 2014;20(21):6357-6363. doi:10.3748/wjg.v20. i21.6357.

2. Newton GE. Maintaining the balance: reconciling the social and judicial costs of medical peer review protection. Ala Law Rev. 2001;52(2):723-742.

3. Hicks CW, Makary MA. A prophet to modern medicine: Ernest Amory Codman. BMJ. 2013;347:f7368. doi:10.1136/bmj. f7368.

4. To Err is Human: Building a Safer Health System. Editors Institute of Medicine (US) Committee on Quality of Health Care in America, Kohn LT, Corrigan JM, Donaldson MS, editors. Source Washington (DC): National Academies Press (US); 2000.

5. Brand RA. Ernest amory codman, MD, 1869-1940. Clin Orthop Relat Res. 2009;467(11):2763-2765. doi:10.1007/s11999-0091047-8.

6. Goldman RL. The reliability of peer assessments of quality of care. JAMA. 1992;267(7):958-960. doi:10.1001/ jama.1992.03480070074034.

7. Edwards MT, Benjamin EM. The process of peer review in US hospitals. J Clin Outcomes Manag. 2009;16(10):461-467.

8. Scheutzow SO. State medical peer review: high cost but no benefit--is it time for a change? Am J Law Med. 1999;25(1):760 .

9. Kelly JP. Peer review immunity after Patrick v. Burget. Healthspan. 1988;5(6):2-5.

10. US Supreme Court. Certiorari to the United States Court of appeals for the ninth circuit; 1988.

11. Kadar N. How courts are protecting unjustified peer review actions against physicians by hospitals. J Am Phys Surg. 2011;16:17-24.

12. Townend DW. Hospital peer review is a kangaroo court. Med Econ. 2000;77(3):133-136, 141.

13. Huntoon LR. Editorial: Sham Peer Review and the Courts. J Am Phys Surg. 2006;11(1):4-5.

14. Arkansas Code Title 20 - 9 -1304 (h). Discussion of the right to legal counsel for the individual subject of peer review, as called under the Health Quality Improvement Act, c.(3) (d)(i).

15. Yaqub v Salinas Memorial Healthcare System, 122 Cal. App. 4th 474 (2004) (Cal. Ct. App. 2004).

16. Rabelo $v$ Nasif and Milford Regional Hospital. Worcester Superior Court Civil Action No. 2011 (2013).

17. Islami v Covenant Medical Center, Inc. 822 F. Supp. 1361, 1370 (N.D. lowa 1992).

18. Edwards MT. Clinical peer review program self-evaluation for US hospitals. Am J Med Qual. 2010;25(6):474-480. doi:10.1177/1062860610371224.

19. Agee C. Improving the peer review process: develop a professional review committee for better and quicker results. Healthc Exec. 2007;22(3):72-73.

\section{Ethical Approval}

Not applicable. 